\title{
Barriers and Motivations Affecting Information Systems Usage by Hajj-Umrah Religious Tourism Operators in Saudi Arabia
}

\author{
Hani Brdesee \\ RMIT University \\ haniid@hotmail.com \\ Brian Corbitt \\ RMIT University \\ brian.corbitt@rmit.edu.au \\ Siddhi Pittayachawan \\ RMIT University \\ siddhi.pittayachawan@rmit.edu.au
}

\begin{abstract}
Hajj \& Umrah religious tourism accounts for seven million visitors each year in Saudi Arabia. The government has recently taken initiatives to promote the use of Information Systems (IS) in the religious tourism industry, encouraging firms to adopt IS innovations like e-commerce and enforcing the use of the Makha'a information system in Umrah for external pilgrims and the Yosr information system in Hajj for internal pilgrims. This study outlines the motivations and challenges that affect the utilisation of various IS services in the Saudi religious tourism industry through a qualitative analysis of the views and perceptions of senior executives and owners of travel firms. The findings suggest that while government initiatives and industry competitiveness were two positive factors promoting IS use, there are some major barriers preventing private firms from fully utilising the advantages of information systems. These include external factors such as lack of support from the IT industry and access to IT resources as well as internal factors within an organisation such as lack of commitment or the need for professional IT expertise. The study finds that relative advantage is a critical contributor to IS utilisation which depends on information systems characteristics.
\end{abstract}

Keywords: Hajj - Umrah, Religious Tourism, Information Systems Use, Technology Adoption, Saudi Arabia

\section{INTRODUCTION}

This research investigates the usage of information systems (IS), particularly e-business through ecommerce and e-management systems, in the religious tourism industry in Saudi Arabia. With the growing tourism potential of the country and the annual Hajj-Umrah pilgrimage that draws in millions of visitors, e-business has come to be seen as a valuable medium for boosting efficiency and profitability in the tourism industry. Efficiencies in IS applications in marketing practice can help the tourism industry achieve cost reduction and greater productivity, (EP-MoH 2012). The aim of this research is to identify the motivations and barriers that influence the use of IS by religious tourism operators in Saudi Arabia. This research will clarify the reasons behind the low level of IS utilisation in tourism firms and help policymakers and industry leaders to undertake measures that can overcome the existing barriers and take further steps to amplify the motivating factors that promote IS use. 
The paper also adds to the understanding of technology adoption in Arab countries by drawing upon generic theories of technology change and using their insights to study the issue of IS utilisation in the specific cultural locale of Saudi Arabia. Although, there is now a greater diversity of literature available on IS research and online marketing, researchers still tend to derive their theories and models from the work in the United States, United Kingdom and Europe. A West-centric bias has tended to dominate the assumptions regarding the mores of international trade and theories on different aspects of business research in academic literature. This study examines a global phenomenon of trade and technology from a standpoint of a non-Western context in its own traditions. While using a generic theory of technology adoption derived from West-based academic literature, this localised focus on Saudi Arabia will also highlight some of the context related dimensions.

\section{RESEARCH BACKGROUND}

With the Red Sea to the west and the Arabian Gulf to the east, the Kingdom of Saudi Arabia occupies the greater part of the Arabian Peninsula. The country's population is estimated to be 26.534 million in July 2012 including the expatriate population in the country which ranges from 5.5 to 6.5 million (World Factbook 2012). Arabic is the native language and English is the lingua franca for social occasions and business purposes. The country is the birthplace of Islam and all Saudi nationals are Muslims and those wishing to seek citizenship must convert to Islam. Islam is the basis of the Saudi society and its constitution, legal system, government and commercial transactions. On a social level, a devout Islamic lifestyle together with Arab customs and traditions forms the foundation of Saudi business culture.

The bulk of tourist traffic comes to Saudi Arabia for the two main religious pilgrimages, Hajj and Umrah. Hajj is an annual pilgrimage that occurs from the $8^{\text {th }}$ to $12^{\text {th }}$ day of Dhu al-Hijjah, the $12^{\text {th }}$ and last month of the Islamic calendar. It commemorates the exodus of the Prophet Mohammed ( محد صلى and his followers from the holy city Makkah to the holy city Medinah in the year 622 CE, marking the beginning of the Hijra or the Islamic calendar. It is obligatory upon every physically and financially capable Muslim, male and female, to make the Hajj pilgrimage at least once during their lifetime. In the last few decades, up to four million people converge every year on Makkah from around the world to attend the Hajj.

There is a subsidiary pilgrimage called Umrah, which may be taken anytime during the year. This pilgrimage is not dedicated to any sacred event or historical date but covers a general tour of holy sites in Makkah and Madinah as well as all other places of historical antiquity and religious importance in this vast area. Pilgrims visit the holy mosques in Makkah and Madinah, complete the devotional act of seven rounds called Sai, and other seven circumambulations called Tawaf around the Kabah (shrine), (Ministry of Hajj 2012). While some people automatically include the Umrah in their Hajj schedule, others consider Umrah as an independent ritual that may be performed separately.

\section{INFORMATION SYSTEMS USE AND THE RELIGIOUS TOURISM INDUSTRY}

In the preceding decades, public or private sector organisations frequently lacked access to IT services. However, recently, the government has taken steps to liberalise the IT market and involve the private sector in this industry to raise the level of Internet use and computer penetration rate to $30 \%$ by 2013 (BMI 2009). The Saudi private sector is responding to the IT challenge by vigorously adopting new technology and investing in the IT sector, (Aldogily 2009; Alzhrani 2009). With its fast-growing population, rising wealth index and growing industry, analysts consider Saudi Arabia a 
market with great potential for IT, (BMI Industry Report 2012). Despite the 2008-2009 economic slowdown, the Kingdom continued to grow as a market for technology products and services as it continued to invest in upgrading its IT infrastructure, and deploying high-speed Internet or mobile transmission facilities (BMI 2009). The Saudi Arabia IT Report by Business Monitor International states that annual per capita expenditure on IT reached \$US330, accounting for around 40\% of IT spending in the Gulf region. Saudi Arabia has the largest IT market in the Gulf region, with a forecast value of US\$3.5bn in 2009 expected to rise to US\$4.8bn by 2013. In terms of IS utilisation for business, the Arab Advisors Group, in its 2009 report, found that Saudi Arabia is leading the region in e-business, registering a record SAR12 billion transactions in the Kingdom in 2008 (TradeArabia 2009). The report further shows that 3.5 million Internet users, or one-eighth of the Saudi population, were engaged in e-commerce transactions.

In the last few decades, Information and Communications Technology (ICT) have evolved in Saudi Arabia from wired to wireless hardware, passive to active software, delivering competitive edge to businesses from diverse sectors of the industry, (BMI Industry Report 2012). Now, Information Systems have become the backbone of many businesses, emerging as the primary vehicle for communicational needs ranging from information storage, human interaction to data transfer. Apart from all these general utilities, e-business and online management of marketing and business operations, is an IS service that holds great promise for the commercial sector in increasing productivity, spreading customer-base and easing logistical difficulties of conducting transactions, (Turban et al. 2010).

The Hajj-Umrah religious tourism industry in Saudi Arabia could gain considerable benefits from ebusiness and IS technologies, (Masoud 2005; EP-MoH 2012; Brdesee et al. 2011; Brdesee et al. 2012). The religious travel and pilgrimage industry in the country is a complex system built up over centuries, but integrating IT efficiencies into its business model could help improve efficiencies and better serve their global clientele of 21 st century Muslim pilgrims. The industry can use IS/e-business portals to provide prospective pilgrims reliable information on the Internet and enable customers to make bookings and complete their transactions swiftly for all travel needs from transport to accommodation. Complexity in travel information, logistical difficulties in communications with the firm or means of payment will simply push potential clients to search for different providers, (Pavic et al. 2007; Hooshang et al. 2006). The organisations can resolve this impasse and market their products to a global or local market of potential clients who are long used to selecting travel services and purchasing them online.

As religious travel in Saudi Arabia involves millions of visitors from all over the world, it is controlled by the government for security and logistics reasons. The government controls and monitors the entry of visitors into the country for pilgrimage, (MoH 2012). Effective IS utilisation in the sector can not only help the government provide an efficient marketing/booking channel but act as an effective monitoring system for all pilgrims in the country. To this end, the government has been motivating providers to use information systems Hajj-Umrah needs, which are then sold by several IT providers, (EP-MoH 2012). To explain further, the Hajj-Umrah industry operates in four basic modes, (MoH 2012):

- Hajj for local Muslims: The Ministry of Hajj in Saudi Arabia offers licenses to about 40 companies for local Hajj pilgrims, which include Saudis and Muslim expatriates living in Saudi Arabia.

- Hajj for external Muslims: The Ministry of Hajj in Saudi Arabia fully controls the arrangements offered by local providers like (Twafaa establishments, مؤسسات الطو افة) in Makkah, (W'okala Office, مكتب الوكلاء الموحد) in Jeddah. 
- Umrah for local Muslims: This group of Umrah packages are meant for Saudis and Muslims expatriates living in the country and here any pilgrimages can retail packages on its own the whole year round.

- Umrah for external Muslims: The Ministry of Hajj in Saudi Arabia licenses about 20 companies as local agents to arrange Umrah for external pilgrims through international agents.

For the purpose of this research, the authors intend to focus on travel firms that conduct two of the above services, namely, Hajj for local Muslims and Umrah for external Muslims. These two packages involve local travel agents who must make use of the current IS and e-business portals to deliver services. The other two groups are excluded because they do not involve local firms or mandatory use of IS systems.

In the case of Hajj for external pilgrims, packages are directly administered by the government and providers such as Twafaa establishments. For non-Muslim countries, there is special arrangement between travel agents in these countries and the Ministry of Hajj in Saudi Arabia, for example, Australian travel agents can provide regular escorted Umrah travel and Hajj packages (Ourworld 2011).

Yosr is a common booking system used for arranging Hajj for local pilgrims. It allows these organisations to register pilgrims, cater for their accommodation and transportation needs, and finalise payments (Yosr 2012). The procedure for Umrah for external pilgrims is much more complex. There is a main IS portal called the (Makha'a, مُخاع) which links all the stakeholders, internal licensed Umrah agents, and external travel agents with the Ministry of Hajj, and the Ministry of the Interior in one information system, (EP-MoH 2012). There are five Makha' $a$ Internet providers and about 40 Umrah agents licensed by the Ministry of Hajj. The government requires designated Umrah pilgrimage providers to work online with their international dealers because local travel agents are not permitted to offer Umrah services directly to the external pilgrims, (EP-MoH 2012).

The Umrah operator begins by creating an Umrah package at a fixed price. Umrah agents are required to administer to the needs of all pilgrims from the time of their arrival at Jeddah airport until the end of their pilgrimage, (EP-MoH 2012). The package offered must address all travel needs, including accommodation, transportation, catering, and additional services such as medical insurance, (EP-MoH 2012). This is then sent to the Ministry of Hajj for approval through Makha'a. When the $\mathrm{MoH}$ approves the package, the Umrah operator offers the package to its external agents outside Saudi to start retailing it to pilgrims. When the external agent has acquired customers, it sends their information to Makha'a for further processing through the Umrah operator. The Makha'a will then send this information to the $\mathrm{MOH}$ to check the data of individual passengers and give each passenger a Ministry of Foreign Affairs (MoFA) approval number, which will be used to issue a visa from the Saudi embassy. The external agent will then be notified through Makha'a to collect the visas from their local embassy for the accepted passengers of the group (Bab Umrah 2012).

\section{LITERATURE REVIEW}

To thrive in any market, most organisations seek competitive advantage through superior products and services, cost controls and competitive pricing, and innovation, (Pavic et al. 2007; Hooshang et al. 2006). Information system solutions have emerged as a primary means for solving a whole range of operational needs from communication to data storage, and in particular, e-business portals have emerged as a cost-effective medium for sales and marketing. Molla and Licker (2005, p.90) note that "organizations that perceive market forces as ready for e-commerce, as an example for information systems, are likely to adopt e-commerce or embark on more sophisticated e-commerce 
implementation from fear of competitive disadvantage or perceived e-commerce benefit". Kshetri (2007) notes, however, that organisations from emerging economies tend to find economic, sociopolitical and cognitive issues with implementing e-business. These include issues relating to legal and financial security and cognitive barriers that relate to knowledge, skill and confidence in using IS. Hence the issue of technology adoption has become a subject of extensive research in marketing and business literature in the last few decades, (Fishbein and Ajzen 1975; Davis et al. 1989; Tornatzky and Fleischer 1990; Davis \& Venkatesh 1996; Molla and Licker 2005, Selim 2008; Suebsin and Gerdsri 2009).

Theoretical modeling is used to explore the acceptance rate for new technologies and many factors affecting ICT adoption can be extracted from these tested models. One such model Innovation Diffusion Theory (IDT) was postulated by Rogers (1962) to explore the factors affecting the adoption or rejection of innovative techniques. The theory proposes that five major factors impact the diffusion of an innovation: Relative advantage, Compatibility, Complexity, Trialability and Observability. Another model called the Theory of Reasoned Action (TRA), posited by Fishbein \& Ajzen (1975), focuses on the subject's intention to act by measuring his propensity to adopt or reject a particular technology. TRA posits that the beliefs and evaluations of the subject determine the user attitudes toward the matter under review (Ajzen and Fishbein 1980). TAM or Technology Adoption Model is another important theory in technology adoption developed by Davis et al. (1989). It posits Perceived Ease of Use and Perceived Usefulness as the two important factors in explaining system usage where Perceived Ease of Use is defined as the extent to which a person believes that using a given technology will save effort and labour and Perceived Usefulness is the extent to which a person believes that the relevant technology will enhance performance of a task.

The adoption of technology within an organisation occurs at two levels: primary adoption within the organisation as a whole, and at the secondary level as it is taken up on an individual basis (Suebsin and Gerdsri 2009). Some scholars find that technology adoption theories such as Technology Acceptance Model (TAM) should focus on individuals' behaviour, not the behaviour of an entire organisation (Davis et al. 1989). But when considering the adoption of IS in an industry as a whole and the manner in which technology emerges as a driver for change within an organisation, there is need to encompass systemic and structural reasons along with individual opinions. The Technology, Organization, and Environment context (TOE) framework developed in 1990 by Tornatzky and Fleischer (1990) takes this broader perspective by examining the overall contextual basis for the adoption of a technology in a particular location. It identifies three aspects of an enterprise's context that can influence the process by which it adopts and implements a technological innovation: technological context, organizational context, and environmental context. The TOE framework as originally presented and later adapted in IT adoption studies, presents an approach that shows greater cognizance of the effect of context on technology adoption. It provides a useful analytical framework for studying the adoption and assimilation of different types of IT innovation in a specific locale.

This study also holds the primacy of contextual factors over individual predilection of executives in matters of technology adoption. The most immediate and compelling reasons for adopting technologies are initiated within a company's own market positioning, strategic vision and operational needs. Business models, objectives and operations vary from one company to another, even in the same industry and this will affect plans regarding IS adoption as well. Organisation's characteristics, such as size, vision and planning (Ke and Wei 2008) as well as subjective factors such as the level of commitment, customer service and leadership by managers affect the use of IS (Nusair et al 2011; Singh et al. 2009). A good business plan in information system use facilitates online strategies and allows the firm to assess and measure its progress and adjust to a new technology or a changing business environment. Researchers have also emphasised the role that certain factors external to the business can exercise in promoting the adoption of a technology. Governments can 
play a crucial role in providing policy, regulations and incentives to encourage private sector to respond to technological change (Molla and Licker 2005). Others emphasise the importance of a spectrum of industry-based motivations, such as strategic positioning, supply chain logistics and information-sharing, in motivating organisations to respond to technology change (Piris et al. 2004; Claycomb et al. 2005). Furthermore, access to sufficient human and technology resources in the national market and their cost-effectiveness has an impact on technology adoption by businesses and enterprises (Ko et al. 2008). As is apparent, researchers tend to cluster these larger structural factors of technology change into variables external to the organisation (industry, government) and internal variables (organisational culture, resources, staff motivation); (Molla and Licker 2005).

\section{RECENT RESEARCH IN SAUDI ARABIA}

Many scholars have studied the challenges in IS utilisation as well as the motivations that have promoted their adoption in several areas like education, business and management in Saudi Arabia (Alkahtani, 1998; Al-Gahtani 2003, Al-Gahtani et al. 2007; Agourram 2009; Al-zharani 2011). AlGahtani (2003) conducted an extensive study on behavioural attitude to IS use of about 1200 knowledge workers in 56 public and private medium and large organizations across Saudi Arabia. Using Fishbein \& Ajzen's Theory of Reasoned Action they examined how attributes of relative advantage, compatibility, complexity, trialability and observability affect IS use and found that these attributes explain up to $87 \%$ of the innovation rate of adoption. In a more focussed small-scale study, Agourram (2009) explored how IS success is defined and perceived by a group of managers in a university in Saudi Arabia using Hofstede's $(1980,2001)$ cultural dimensions. It found that culture does influence perceptions of IS success which poses problems particularly to organizations that decide to implement Enterprise resource planning systems (ERP). Al-Gahtani et al. (2007) conducted a comparative study of IT acceptance in North America and Saudi Arabia using a modified model of TAM called the unified theory of acceptance and use of technology (UTAUT). UTAUT examined the influences of select antecedent social influence and cognitive instrumental constructs on perceived usefulness and usage intentions (Venkatesh, Morris, Davis \& Davis 2003). Hofstede (1980, 2001) cultural dimensions were also used to show the degree of difference between North American and Saudi Arabian adoption of IT. The authors found that some aspects of behavioural intention and deterrents to usage had real impact on IT adoption in Saudi Arabia. A study by Al-zharani (2011) examined the perceptions and difficulties of IS implementers at both government and private sectors. Lack of coordination within and between Saudi organisations as well as issues associated with technical, behavioural and structural factors were found to impede IS implementation.

As apparent from this review, several studies have been conducted on different aspects of IS use in different organisational contexts in Saudi Arabia. The millions of pilgrims who enter the country for Hajj and Umrah pose severe logistical challenges as well as business opportunities which could be better addressed by sophisticated IS and e-commerce portals.

Furthermore, the religious tourism industry of Hajj and Umrah in Saudi Arabia is sufficiently large and mature to attract research for directing its growth. This has motivated researchers to study and find solutions from IS for a host of problems like crowd management and tracking. For example, Khozium (2012) conducted research to design an information system that could manage crowds during the (Nafra, النفرة) ritual at Hajj when about 3 million of pilgrimages move from Arafat to Muzdalifa on one holy night. Using thermal cameras as sensors at strategic points and roads, a computer interface fuzzy logic, operations research and decision support was developed to produce alternate decisions to the system controllers enabling them to control the movement of the huge crowd. As the movement of vehicles and mass transit during Hajj is a major challenge facing urban planners and designers in Makkah, Koshak (2006) used web-based Geographic Information System 
(GIS) to provide broader and easier distribution of the traffic plan that could facilitate easier understanding and adherence to the traffic plan. In another study, Amro and Nijem (2012) proposed a communication and information system that could assist tourist guides (Mutawwif) in organising the movement of pilgrims in their group and add new capabilities for incidental difficulties such as lost pilgrims, and predict and avoid possible lost ones. Naser et al. (2010) studied the usability and the risks and limitations of Radio Frequency Identification (RFID) technology in managing security issues, organizing pilgrims' movement, residential management, healthcare management, luggage tracking and E-passport. While these studies are concerned with the implementation and limitation of specific IS instruments, Masoud (2005) focused on the vital role played by IT in supporting the development of Saudi tourism industry and in particular the assessment of the efficiency and capability of the economic performance. The study showed a positive impact of IS-based portals on the quality of tourism services, the ability of controlling mechanism to regulate demand and supply as well as the possibility of increasing the regular income of tourism operators.

\section{RESEARCH GOAL}

As this review shows, there are quite a few studies on IS use in the tourism industry in Saudi Arabia, but the specific focus adopted in these studies are also accompanied with some limitations. As pointed out earlier, one limitation is that most of these studies apart from Masoud (2005) focus on specific technical applications of some IS instrument and not the wider impact of IS use for the tourism industry in general. Secondly, even Masoud's study is more concerned with enumerating the positive benefits of IS use rather than problematising the use and adoption of IS for the tourism industry. Also, most of these studies have focused on the end-user not organisational usage, but as it was argued earlier systemic factors in the environment are critical to the adoption and use of various information systems within an organisation or an industry as a whole. In light of these limitations of the existing research on IS use in the Saudi religious tourism industry, the present study makes a substantial intervention insofar as it takes a macro-perspective on the issue of IS use in the religious tourism industry and accounts for internal and external factors constituting organisational as well as cultural motivations that impact IS use.

\section{METHODOLOGY}

This paper used a interviews to discover the beliefs and attitudes of executives of Saudi religious tourism organisations and identify the factors influencing the adoption of various IS. Jeddah was selected as the site for the research and ten firms in the Hajj and Umrah service or both, were approached for interviews. The majority of participating firms in this study were registered tourism organisations licensed by the Ministry of Hajj and/or members of the Jeddah Chamber of Commerce and Industry and listed on the Chamber's websites. Jeddah is the gateway to the two holy cities at Makkah and Al-Madinah. As the entry point for pilgrims on Hajj or Umrah, pilgrims may also spend time around Jeddah, visiting its other attractions, historical monuments, art and culture.

Potential respondents were invited by telephone or email to participate in the study, and received letters explaining the study, approximate appointment times and dates with individual consent forms for signature. Seven firms were interested in participating in the study, of which only five were finally able to participate. Once interview times were mutually finalised, the interviews were conducted at each firm's premises. The data was collected through semi-structured interviews and audio-taped with the respondent's consent. Open-ended interview questions were used to minimise influence on the participants' responses (Bryman and Bell 2007). 


\begin{tabular}{|l|l|l|l|l|}
\hline Participant & Qualification & age & Experience & Industry sector \\
\hline P.1 & $\begin{array}{l}\text { Masters } \\
\text { (Bus. admin) }\end{array}$ & $25+$ & 7 years & Religious tourism (Hajj) \\
\hline P.2 & $\begin{array}{l}\text { PhD } \\
\text { (Strategic mgmt) }\end{array}$ & $50 \mathrm{~s}$ & 32 years & Religious tourism (Hajj) \\
\hline P.3 & $\begin{array}{l}\text { Masters } \\
\text { (Bus. admin) }\end{array}$ & $40 \mathrm{~s}$ & 22 years & $\begin{array}{l}\text { Accommodation \& religious } \\
\text { tourism (Umrah) }\end{array}$ \\
\hline P.4 & Diploma (Commerce) & $60 \mathrm{~s}$ & 40 years & $\begin{array}{l}\text { Religious tourism (Hajj \& } \\
\text { Umrah) }\end{array}$ \\
\hline P.5 & Not advised & $40 \mathrm{~s}$ & 23 years & Travel agency (Umrah) \\
\hline
\end{tabular}

Table1. Interviewee profiles

The interviews recorded on the audiotapes were transcribed and the feedback from the respondents were arranged and coded for common themes to facilitate analysis and comparison with the scholarly literature. The interpretation of the collected data plays an equally important role in the actual analysis as the actual collection of data (Kval and Brinkmann 2009). Interpretation is not merely a simple reading of the text but a process of actively creating meaningful ideas and concepts from the text, (Creswell 2009). A variety of approaches can be used for interpreting texts, the most important of which is the hermeneutical approach. Originating from German philosophical tradition, the hermeneutical approach developed out of a dilemma about how meaning is constituted in human speech and actions (Dilthey 1988). Hermeneutics is a means of textual interpretation or finding meaning in the written word through a process of "structuring of the manifest of what is said to deeper and more critical interpretation of the text" (Kvale and Brinkmann 2009, p207). As an art and science of interpreting meanings, hermeneutics also emphasises the socio-cultural and historic influences on the way in which a certain phenomenon is perceived or interpreted.

The reliability and validity of the data collected in any qualitative research is of prime importance (Creswell 2009). Many steps were taken to ensure reliability of the collected data. First, the authors checked transcripts to make sure that they did not contain any mistakes made during the transcription. Second, they checked the data to ensure that the meanings of the codes were free from shift or drift in definition. Third, a coordinated communication among the coders took place for sharing codes and analysis and cross-checking of results.

The authors also used rich and detailed descriptions to convey the findings of the research. Rich and detailed description, providing cohesive and information about all facets of the collected data, make it more realistic and coherent (Creswell 2009). Also, the main author spent extensive time in the field, studying the Hajj \& Umrah industry and conducting field research for about three months in Jeddah city. Creswell (2009) stresses the importance of spending time in the field as it helps convey details about the site and people under research that lend credibility and accuracy to its findings. Furthermore, the authors did not edit negative or odd findings that run counter to the theme under discussion and presented them without bias. Such different or contrarian perspectives to an issue can actually enhance the credibility of the research as honest acceptance and presentation of contradictory evidence lends realism to the research conducted (Creswell 2009). 


\section{ANALYSIS \& DISCUSSION}

This section considers the results from the analysis categorised on the basis of the key factors motivating IS use. These include internal factors of market condition, customer influence, organisational commitment and industry competiveness, while government initiatives and supporting ICT industry are classified separately as external factors motivating IS utilisation. Each of these themes is also accompanied by a selective reporting of some noteworthy responses from the participants 1

\section{External Support}

\section{Government Initiative}

The majority of participants in this study accepted that the use of IS had enhanced their productivity, particularly in improving work processes. This shift, however, had occurred not entirely of the firms' own volition but because of government intervention, as the Saudi government required all businesses involved in Umrah religious travel to operate online and encourages e-business in the Hajj \& Umrah industry. This finding echoes some studies which find that economies subject to government regulation in ICT adopt technology more than others who are not so affected by government control (Molla and Licker 2005).

One participant, P2, the Motawef (a representative of a Twafa establishment) for external Hajj pilgrims, said that he valued the Ministry of Hajj's information system, used by all Motawef offices to record and process Hajj activities, and issue visas. Another participant, P1, noted the minor positive effects of supplementary information from the ministries' websites.

"Information on the Ministry of Hajj and Ministry of Islamic Affairs, 'Da'wah, Guidance and Endowments' website assisted us in creating a well-informed online system. We uploaded and re-formatted details to offer an easier understanding of Hajj. Pilgrims appreciate this additional information and it gives them a positive impression of our services" [P.1].

A manager from hotel chain and external Umrah agency, P3, stated that the government's compulsory national information system (Makha'a, مخاع) is the main reason for the successful implementation of IS in this industry.

"The reason we use Makha'a is because the Ministry of Hajj dictates that its use is a condition of an Umrah licence. We have to renew our contract annually with a Makha'a's IT provider but we have the choice to select which provider's Makha'a system we prefer" [P3].

In the same context, participant P4 mentioned the example of online banking, arguing that Saudis only used online banking because most public and government sectors, like electricity bills, telecommunications and other governmental services like passport renewal, have encouraged their clients for transactions to be conducted online. This respondent said that people would not have shifted to booking online without this type of enforcement by the government.

\footnotetext{
${ }^{1}$ Note that the participants are signified by the letter [P. Participant Number].
} 
"Let's take electronic banking services as an example. People did not use these services until the government made it compulsory to proceed most services online with payments and changed physical transactions, for example passports and other public sector accounts" [P.4].

The majority of participants argued that there was insufficient government action in the form of regulations, infrastructure and programs to support local business. The absence of these government initiatives was a major barrier to the productivity of fully integrated IS adoption in all kinds of services in the Hajj \& Umrah industry. Participant P4 explained:

"Generally, people responsible for building the infrastructure only consider current needs and probable usage when designing the equipment. They do not consider future needs as they are uncertain of returns or high costs in such speculative action" [P.4].

However, surprisingly, participant P4 thought that in spite of these benefits of IS use and the existing lack of IS implementation in the tourism industry, the current legislation was sufficient.

"I don't believe that there is a need for more legislation for e-business, because the courts for commercial conflicts can also consider those that occur online” [P.4].

On the whole, the participants acknowledged the critical importance of government intervention and believed that the government could further extend its administrative powers to make the ICT channels even more useful and efficient. Several participants suggested that government could encourage the uptake of IS by making it more difficult for businesses to file paper forms for licenses, or by improving ministerial portals for e-government.

\section{Supporting ICT industry}

Access to inexpensive, efficient and advanced ICT resources and infrastructure was a critical issue for many respondents. If the ICT service and infrastructure in the market is deficient, no businesses would consider investing in such services. Participants expressed concern about the quality of the Internet connections, saying that lack of speed and reliability in Internet connection could completely jeopardise e-business in the industry.

Some participants noted that the recent innovation in online licensing and marketing had improved the access of travel agents to IT resources and expertise for conducting their business. P1's organisation used an online portal (Yosr, يسر), which assists many Hajj providers for internal Hajj pilgrims to organise their client travel data from registration to the end of Hajj rituals. The annual cost of the portal is reasonable as development costs are shared by all Hajj travel providers and this reduced the cost of groups purchasing ICT services.

"We had an ERP [enterprise resource planning] information system specified for our company. It was fine for our needs at that time, but the annual cost was prohibitive. However, when we moved to Yosr, technological advances were absorbed by many firms at reasonable prices because it is available for many Hajj travel providers" [P.1].

Another participant, an Umrah agent, praised the utility of the Makha'a system in these words:

"The conditions of our contract with the Ministry of Interior include permission to approve inclusion of the pilgrims to Umrah and the numbers of pilgrims are also referred to the Ministry of the Hajj. We could not productively administer this trade without the online system" [P.3]. 
The participants were aware that there are certain deficiencies in the local IT providers and they talked at length about the absence of qualified IS providers. One could observe that there was reluctance among participants from the larger and more sophisticated travel firms to employ local ICT support firms due to a perceived lack of competence.

"For market advantage, we would have no problem in establishing global computer systems immediately. If you know a firm that can perform, please let me talk to them. We usually seek out new technologies. For example, we contracted a global provider for a customer relations system, but we cannot find local IT companies with sufficient professional expertise" [P.5].

Some participants also commented on the cost of services provided by ICT providers. While participants realised that higher quality would cost more, they said that they often found these costs to be prohibitive. The size of their business and profitability determined their ability to justify the outlay for elaborate information system and online services. Small and medium sized organisations were not able to afford high cost information system and e-business solutions.

"Local IT companies inflate the costs in their quotations for websites with online sales, I do not know why ... even testing a trial version is so expensive ... I searched for some other services as well and I found much better solutions than what we have but they would cost us 10 times more . . you should keep the cost in mind, cost is a critical factor" [P.3].

While most participants appreciate the creation of the Yosr and Makha'a online booking systems, their comments and suggestions reveal the need for further improvements of ICT providers' availability and capability, and IS affordability. In addition, the large data transfers and information storage for the travel industry are required via excellent technology, appropriate networking and skilled operators.

\section{Internal capability}

\section{Human Resources}

The access to requisite IT infrastructure also depends on the degree of sophistication of the IT expertise in the country, (Brdesee et al. 2011). The web developers, programmers and designers who work for the local firms are expatriates. As the majority of these workers are not fluent in Arabic, the travel operators have difficulty in communicating their needs and the resultant e-business portals are not sufficiently attractive or compatible to induce customers to buy their services.

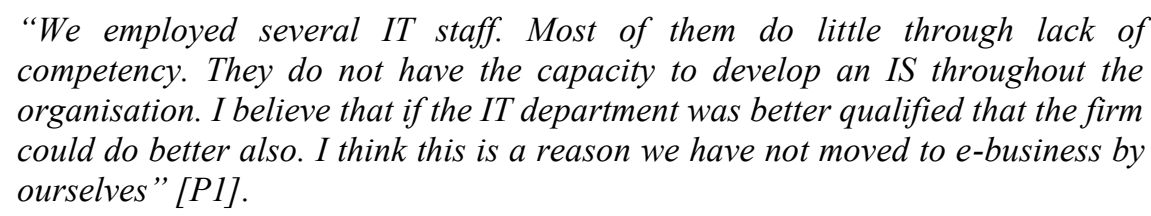

To tackle this issue, a participant said that his corporation had developed its online booking website in Canada by people of Arabic background.

\section{Business model}

Participants were of the opinion that the extent of investment and adoption of IT depended on that internal business plan and strategic vision, (Brdesee et al. 2012a, Brdesee et al. 2012b). The chief executive officer, or the owner, often made these crucial decisions about technology adoption. 
E-readiness in a business model encompasses themes such as the organisation's understanding of the online environment, its support of automated trading, strategic requirement and commitment to systems change. Therefore, lack of commitment contributes considerably to absence of an online business. ICT awareness and competency of the manager also affects the level of technology adoption. Participant P4 explained his business plan and model in relation to IS adoption:

"We do not have any current plans to invest further in information technology, because our information systems perform well. But we are focusing on expanding our bus fleet and building or buying new hotels. Yet, this does not mean we are not going to adopt new technology if it proves to be necessary" [P.4]

Participant P5 indicated that his firm was undertaking ICT development but this was not necessarily directed at IS implementation for marketing and e-business.

"We focus on internal development more than planning electronic business. We are restructuring our organisation with new organisational services and profit centres. We recently moved from paper to online records and our workers are being trained in the new systems. It is an expensive program for staff-training in 15 locations and we have to ensure that all records are changed over successfully as well" [P.5]

If the manager does not understand the nature of the technology, or is unable to evaluate the available technology to meet the firm's needs, then there is disconnect between need and procurement, and uncertainty about successful implementation prevails.

\section{Relative Advantage}

\section{Market Condition}

While IS may have its benefits for religious tourism industry, the demand of customers for such services is what actually determines the level and extent to which firms implement such services. Some participants were sceptical about the popularity of e-commerce and the number of customers who would book online. Participant P3, a representative of a national hotel and Umrah agency, argued that the size of the potential market was a critical factor in the adoption of e-commerce.

"The whole issue [of online booking system] has been on my mind for a while, but a visitor from Egypt, for example, is not going to be able to book online due to Saudi visa restrictions. In this case I can only offer online bookings to citizens of the Arab Gulf countries, expatriates living in Saudi, and local Saudi nationals" [P.3].

On the other hand, a Hajj agent said that there was no sense in investing in an IS ticketing or marketing system for local customers since they would prefer to come directly to the shop. Since the government dealt directly with international operators for international Hajj pilgrims, he could only have the business of local customers and in the domestic market, "e-commerce was fairly ineffective".

These examples show that varied access to different market types for religious travel influences firms' business decisions in adopting IS. Similarly, P2, a Hajj provider to non-Saudi pilgrims (a Motawef, (مطوف and a Twafaa senior officer explained how their service to international pilgrims only begins with their arrival in the country.

"Hajj pilgrims from any Muslim country can apply to governments or Hajj organisers in their countries. We do not have any input at this stage. Our 
mission starts when we receive the pilgrim in Saudi Arabia, we cannot undertake any marketing in those countries" [p.2]

Non-business travellers to Saudi Arabia are restricted by severe visa constraints. Due to security concerns and the logistics of conducting the annual Hajj, Saudi visas for Umrah and Hajj pilgrims are only available through national and international agents who book services with designated Saudi providers. This restricts the share of international leisure and travel markets in the Saudi tourism industry. In support of P3's view, two other providers noted that given the limited number of external pilgrims for Hajj and Umrah each year, agents do not see a need for online booking catering to international tourists as their allocations are easily sold to local customers through their shopfront stores. P1 and P4 noted:
"I think only 2\% of our clients would book online for Hajj. Thus, the investment in an e-booking system would be costly, and the potential number of customers very low, that is way I'm not motivated to go online. Also, each Hajj agent is assessed and graded by the government and this grade affects the pilgrim package allocation. For example, we are grade A, so we are allocated sales for a thousand pilgrims. I can sell this number of vacancies without an e-booking system" [P.1].
"We get a number of vacancies each season from the Ministry of Hajj. We depend highly on referrals to market those vacancies. Most of our customers use word of mouth in their selection of Hajj agent. I don't think there is any need for e-commerce in our case" [P.4].

These tourism executives were of the opinion that Saudis would perhaps not purchase travel services online. They were satisfied with their business within the local market and did not want to extend their customer base globally though e-commerce channels.

\section{Customer service}

Different types of sales channels are exploited by firms, whether it be a shopfront, direct contact through telemarketing, or online marketing, but people's perceptions of the security and efficiency of a particular system may differ. Here, participants stated that older people may not trust the Internet for payment. Other comments were made regarding customer trust, security issues, issues with prototypes on e-shopping, and payment logistics were other reasons cited by some participants. P3 was convinced that fear of fraud and robbery were uppermost on the minds of potential customers.

Some interviewees also believed that online sales could not engage the customer more directly and build rapport and trust between the travel firm and a potentially long-term customer. Participants P1 and P4 said:

"It is an aim of my company to go online, but we will not be able to have personalised customer relations in this medium. From experience, most of our customers make their Hajj arrangements through our company because they trust our staff. This advantage will not be available on the Internet ... I also do not believe other technologies can duplicate the process of meeting customers and talking through their travel plans" [P.1].

"Arabs naturally prefer the opportunity to see what they are buying, not just to hear about it ... you can see how busy travel agents in shops are. Customers go to the agents to meet the agent, talk about their plans, build a trusting relationship and negotiate prices" [P.4]. 
These comments highlighted the importance of customer service and personal interaction especially in a market like religious tourism in Saudi Arabia which can be heavily influenced by traditional business practices.

The use Yosr and Makha'a information systems are two good examples of customer relation management information systems. However, in e-business, the principle of face-to-face rapport, trustbuilding and negotiation may be declining as these firms reach out to a clientele of global Muslims dispersed across the world, and here e-commerce portals can come in to provide a direct interface for conducting such transactions.

\section{Competitive advantage}

The level of IS implementation and its penetration in a single firm is subject to the prevailing standards in the industry as a whole. This study found that participants' firms display competitive behaviour and adopt technological change only when the rest of the industry had adopted those technologies like ICT. Two participants P3 and P1 gave examples of competitive advantage that could affect their responses.

"This is the nature of people. Yes, if my competitor was successful with an initiative, I would definitely follow, but I need to be sure that when I invest one riyal in e-commerce, I get back ten. I can give you an example on the impact of competition. In the nineties, Mercedes and BMW dominated the global luxury car business. Then the Japanese introduced the Lexus with higher standards and cheaper prices. What happened? The two brands improved their standards to retain their positions in the market" [P.3].

But competitive innovation also requires justification and $\mathrm{P} 1$, a licensed Hajj provider for local pilgrims, said that a competitor in the Saudi religious tourism does not adopt innovative advantage unless a real threat to the business is detected.

"My competitors could use an information systems to offer a more convenient managing and marketing channel. I won't respond immediately, but will wait and see what happens. If I feel certain that this is working for them and is negatively affecting my business, then I will plan a change" [P.1].

The majority of participants accepted that IS portals can provide competitive advantage, but they said they would only adopt those services once it was established in their industry and they were convinced that it was financially feasible. Participants commented on competitive advantage about seventeen times during the interviews, and this reflected their attention to the importance of this issue.

\section{SUMMARY OF RESULTS}

The analysis of the participants' responses has confirmed some of the organisational factors as well as the external factors identified in the literature on IS adoption (Rogers 1962; Rogers 2003; Tornatzky and Fleischer 1990; Molla and Licker 2005; Al-Gahtani et al. 2007; Suebsin and Gerdsri 2009) as discussed in the literature review. The analysis shows that the advantages of all information systems discussed is perceived, but the adoption level is dependent on the characteristics of the information system. For example, e-commerce and has some security, trust and perceived relative advantage by religious tourism limitations that hinder its adoption. However, the management information systems like Yosr and Makha'a have some motivational characteristics that promote their adoption like government enforcement and affordability. 
The following factors affect Information Systems usage by Hajj-Umrah religious tourism operators in Saudi Arabia:

External Factors (Government Initiative and Supporting ICT industry): Government initiative is one of the critical factors behind the use of IS in the industry. The industry in general, is appreciative of the steps taken by the government, especially in encouraging centralised IS Makha'a systems. However, the participating executives are seeking further solutions to overcome existing legal and infrastructural obstacles for further IS development. On the other hand, participants were critical of the ICT support industry and said that the relative backwardness of the local ICT industry had discouraged some operators from adopting IS systems like e-commerce. There was also a prevailing perception that the quality of service of local providers was inferior to international ICT support firms. It was also pointed out that while local ICT providers, particularly website developers, were substandard, their costs were significantly higher than those prevailing in the global market for a particular service.

Internal capability (Human Resources and Business model): Apart from broader systemic factors in the Saudi industry, the individual business model of the company and its e-readiness was also critical to IS adoption. The organisations also need staff that can handle and maintain IS systems. Also, skilled staff with well qualifications and visions are required to take their organisations to a further step toward IS utilisation. Organisational commitment to adapt to IS or automated systems can also play a major role. Some organisations give the IS usage and implementation high priority. These organisations are more likely to overcome any further obstacles. The individual business model of the company and its e-readiness also determines IS adoption.

Relative Advantage: The analysis shows that relative advantage of IS is an important factor. Relative Advantage of IS is predicated on the advantages it provides in terms of cost benefit, productivity, time-saving, profit generation and customer service. It must, however, be noted that as the majority of firms did not have an online strategy, cost effectiveness and profit generation were only mentioned by the minority whose business model included or depended on online sales.

\section{CONCLUSION}

From this analysis of data from a series of interviews with Saudi religious tourism operators, this study has examined the perceptions of managers and owners to identify factors motivating IS use. Government initiative is one of the critical issues influencing IS use in the industry, and government intervention through the creation of mandatory e-business portal, Makha'a and Yosr, is in the major reason behind the existing practice of IS use by Hajj/ Umrah operators. Competitiveness in the travel industry as a whole could also prove to be a potential factor motivating individual firms to adopt IS. If IS use was found to provide relative advantage to a company, competitors would soon follow suit. However, problems in accessing ICT resources and the relative backwardness of the local ICT industry have discouraged some operators from adopting IS. In addition, their perceptions about customer service also negatively impacted IS use as most participants generally felt sceptical about ebusiness, preferring a shopfront approach rather than the onerous work of instituting IS without reaping nay benefits in terms of increased sales.

These research findings can be further analysed to develop recommendations for both government policymakers and industry leaders in the field. The study contends that the endings are also valuable for practitioners from western cultures in applying computer-based information systems solutions to developing countries. It can also be used for future research to theorise about the motivations and barriers to IS use in Arab or Islamic contexts. 


\section{LIMITATIONS AND FUTURE RESEARCH}

Limitations of this research resemble those that are inherent in any qualitative research concerning a single geographic location with a restricted composition of study participants. The researchers has no experience in the field of tourism and marketing, however the long time the main author has spent in Saudi Arabia investigating the tourism market would overcome this limitation.

Future research should be conducted in other organisational settings in Saudi Arabia to determine if similar factors influence IS adoption and test the generaliseability of the findings of this study at least within the Saudi market. A study with a quantitative approach using statistical analysis may be conducted to test the validity and interpretability of the findings of this qualitative study. It is recommended that the suggested research model in figure 1 should be considered for future work with further rigorous analysis. The model needs to be tested with appropriate factor analysis tools to understand the interrelation between the constructs and evaluate the validity of the construct of its Factors.

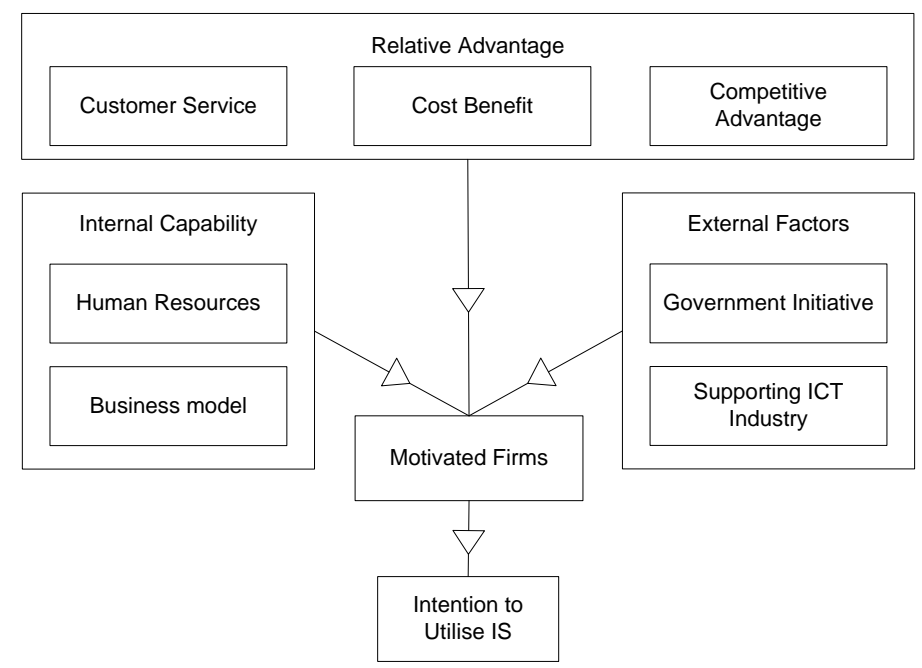

Figure 1: the suggested research model for future work, motivations affecting Information Systems usage

Further, A longitudinal research may be conducted to examine the change in perceptions of IS use among managers/owners in the tourism industry over time. In fact, a study focussed on the point of view by the IS industry executives may be undertaken to highlight any dichotomies between the management and employees in the tourism industry in engaging IS.

\section{ACKNOWLEDGEMENTS}

The main researcher's work is sponsored by Jeddah Community College at King Abdulaziz University, Jeddah, Saudi Arabia. Thus, he would like thank them for their support. However, the authors would like to thank the participants of the study for their insights on the issue and willingness to participate in the study. 


\section{REFERENCES}

Agourram H (2009) The quest for information systems success in Saudi Arabia. A case study. Bishop's university, Lennoxville, Canada.

Ajzen I, Fishbein M (1980) Understanding attitudes and predicting social behaviour. Prentice-Hall, Englewood Cliffs, NJ.

Aldogily M (2009) Saudi Arabia at First in E-commerce Expansion. Alriyadh News, No.14999. http://www.alriyadh.com/2009/07/18/article445570.html. Accessed 10 November 2012

Al-Gahtani S (2003) Computer technology adoption in Saudi Arabia: Correlates of perceived innovation attributes. Information Technology for Development 10:57-69. doi:10.1002/itdj.1590100106

Al-Gahtani S, Hubona G, Wang J (2007) Information technology (IT) in Saudi Arabia: culture and the acceptance and use of IT. Information and Management 44(8):681-691. doi:org/10.1016/j.im.2007.09.002

Alkahtani Mufleh M (1998) Computer-based information systems and their use by managers in Saudi Arabia and the UK. Mufleh M. Alkahtani. http://dspace.lboro.ac.uk/dspacejspui/handle/2134/7759. Accessed 26 June 2011

Al-zharani S (2011) An Empirical Investigation of the Information Technology Implementation in Saudi Arabia. Journal of Information \& Systems Management 1(1):37-45.

Alzhrani S (2009) Alrajhi Banks of Secure Payment System for E-commerce Transactions. Okaz News, No. 2974. http://www.okaz.com.sa/new/Issues/20090808/Con20090808297179.htm. Accessed 3 November 2009

Amro A, Nijem Q (2012) Pilgrims "Hajj" Tracking System (e-Mutawwif).Contemporary Engineering Sciences 5(9):437-446.

BabUmrah (2012) eUmra industry. Bab Umrah. http://www.babalumra.com/en/aboutus.asp. Accessed 27 June 2012

BMI (Business Monitor International) (2009) Saudi Arabia Information Technology Report Q4 2009. Business Monitor International, London, England

BMI Industry Report (2012) Saudi Arabia Information Technology Report - Q2 2012. Business Monitor International. London, United Kingdom, London.

Brdesee, H, Corbitt, B, \& Pittayachawan, S (2011): Technology for business: Supporting industries as a main driving force for e-commerce adoption in Saudi Arabia, In: proceeding of the 11th International Conference on e-Business (pp. 175-180), Spain: Seville.

Brdesee, H, Corbitt, B, Pittayachawan, S, \& Alsaggaf, W (2012a): Organisational culture and adoption of electronic commerce: A study of the Saudi Arabian tourism market, In: proceeding of the 7th International Conference on Computer Science \& Education (pp. 857-862), Australia: Melbourne.

Brdesee, H, Corbitt, B, Pittayachawan, S, (2012b): Lessons to be learnt: cultural means impeding ecommerce adoption in a Saudi industry, International Journal of E-Education, E-Business, EManagement and E-Learning, 2( 6): 488-492.

Cabrera A, Cabrera F, Barajasc S (2001) The key role of organisational culture in a multi-system view of technology-driven change. International Journal of Information Management 21(2): 245-26.

Claycomb C, Iyer K, Germain R (2005) Predicting the level of B2B e-commerce in industrial organisations. Industrial Marketing Management 34(3):21-234. 
Creswell J (2009) Research Design Qualitative, Quantitative and Mixed Methods Approaches. 3rd edn. Sage. CA: Thousand Oaks.

Davis FD (1989) Perceived usefulness perceived ease of use and user acceptance of information technology. MIS Quarterly 13(3):319-340.

Dilthey W (1988) Introduction to the human sciences: An attempt to lay a foundation for the study of society and history. (R. J. Betzanos, Trans.). Detroit. MI: Wayne State University. (Original work published in 1883)

EP-MoH (Electtronic Poortal of Ministry of Hajj) (2012) Process of Umrah for External Pligrmiages. http://www.haj.gov.sa/Pages/UmrahOutProcedures.aspx. Accessed 25 November 2012

Fishbein M, Ajzen I (1975) Belief, attitude, intention and behavior: an introduction to theory and research. Addison-Wesley, Reading, MA.

Hofstede G (1980) Cultural consequences: international differences in work related values. Sage, Beverly Hills, CA.

Hofstede G J (2000) You must have been at a different meeting: enacting culture clash in the international office of the future. Journal of Global Information Technology Management 3(2):42-58.

Hooshang MB, Esmail Salehi-Sangari, Engstrom A (2006) Competitive Advantage with E-Business: a Survey of Large American and Swedish Firms. Competitiveness Review 16(2): 150-157

Ke W, Wei K K (2008) Organizational culture and leadership in ERP implementation. Decision Support Systems 45(2):208-218.

Khozium M (2012) A Hybrid Intelligent Information System for the Administration of Massive Mass of Hajjis. Life Science Journal, 9(4):171-180

Ko E, Kim S H, Kim M, Woo J Y (2008) Organisational characteristics and the CRM adoption process. Journal of Business Research 61(1):65-74.

Koshak N (2006) Developing a Web-Based GIS for Hajj Traffic Plan (HajjGIS.Net). Journal of Urban Planning Research, Cairo University 6(6): 1-13

Kshetri N (2007) Barriers to e-commerce and competitive business models in developing countries: a case study. Electronic Commerce Research and Applications 6(4): 443-452.

Kvale S, Brinkmann S (2009) Inter Views: Learning the Craft of Qualitative Research Interviewing. Sage Publications Inc, USA

Masoud R (2005) Tourism Information System and its Impact on Economic Performance Indicators in Saudi Arabia: An Empirical study on Jeddah district. Unpublished Dissertation. http://islamiccenter.kau.edu.sa/arabic/Maktabah/Rasael/r656.pdf

Ministry of Hajj (2012) Notes on different types of Tawaf. http://www.hajinformation.com/main/f35.htm. Accessed 25 November 2012

$\mathrm{MoH}$ (2012) Responsibilities of the Ministry of Hajj. http://www.hajinformation.com/main/m10.htm. Accessed 10 November 2012

Molla A, Licker P S (2005) E-commerce adoption in developing countries: a model and instrument. Information \& Management 42(6):877-899.

Naser M, Rafie M, Budiarto R, Alsalihy W (2010) Security Considerations in Embedding RFID in 'Hajj' System. European Journal of Scientific Research 42(1):133-138

Nusair K, Parsa N G, Cobanoglu C (2011) Building a model of commitment for generation Y: an empirical study on e-travel retailers. Tourism Management 32(4): 833-843. 
Osterwalder A, Pigneur Y (2002) E-reality: constructing the e-economy: An e-business model ontology for modeling e-business. In: proceeding of the 15th Bled Electronic Commerce Conference, Bled: Slovenia, 2002

Ourworld Travel (2011) Hajj 2012/1433h packages. Ourworld Travel, Wollongong, NSW. http://www.duniana.com/hajj-travel.php\#details. Accessed 20 May 2012

Pavic S, SCL Koh, Simpson M, Padmore J (2007) Could e-business create a competitive advantage in UK SMEs?. Benchmarking 14(3): 320-351

Piris L, Fitzgerald G, Serrano A (2004) Strategic motivators and expected benefits from, e-commerce in traditional organisations. International Journal of Information Management 24(6):489-506

Roger E M (1962) Diffusion of Innovation. The Free Press, 1st edn, New York, NY.

Singh M P, Chopra A K, Desai N (2009) Commitment-based service-oriented architecture. Computer 42(11): 72-79

Soundvision (2012) Umrah and Hajj. Soundvision. http://soundvision.com/Info/hajj/hajj05.asp. Accessed 27 June 2012

Tornatzky L, Fleischer M (1990) The process of technology innovation. Lexington, MA, Lexington Books.

TradeArabia (2009) Saudi tops in E-commerce Transactions. http://www.highbeam.com/doc/1G1203635495.html. Accessed 21 January 2011

Vanderstoep S, Johnston D (2009) Research methods for everyday life: blending quantitative and quantitative approaches. John Wiley. San Francisco: CA.

Wagner JA, Hollenbeck JR (2010) Organizational behaviour: seeking competitive advantage. Routledge, New York: NY.

World Factbook (2012) Country Data Population 2012. World Factbook. https://www.cia.gov/library/publications/the-world-factbook/geos/sa.html. Accessed 19 November 2012

Yosr (2012) Yosr functions. Yosr for Hajj. http://www.yosr4haj.com/. Accessed 27 June 2012 